\title{
Article \\ The Oxidation of Equol by Tyrosinase Produces a Unique Di-ortho-Quinone: Possible Implications for Melanocyte Toxicity
}

\author{
Hitomi Tanaka ${ }^{1,2}$, Shosuke Ito ${ }^{2}\left(\mathbb{D}\right.$, Makoto Ojika ${ }^{3}\left(\mathbb{D}\right.$, Tomoko Nishimaki-Mogami ${ }^{4}$, Kazunari Kondo ${ }^{4}$ \\ and Kazumasa Wakamatsu ${ }^{2, * \mathbb{D}}$ \\ 1 Department of Medical Technology, School of Health Sciences, Gifu University of Medical Science, 795-1 \\ Nagamine, Ichihiraga, Seki 510-3892, Japan; hitanaka@u-gifu-ms.ac.jp \\ 2 Institute for Melanin Chemistry, Fujita Health University, 1-98 Dengakugakubo, Kutsukake-cho, \\ Toyoake 470-1192, Japan; sito@fujita-hu.ac.jp \\ 3 Graduate School of Bioagricultural Sciences, Nagoya University, Chikusa-ku, Nagoya 464-8601, Japan; \\ ojika@agr.nagoya-u.ac.jp \\ 4 Division of Biochemistry, National Institute of Health Sciences, Kawasaki-ku, Kawasaki 210-9501, Japan \\ mogami@nihs.go.jp (T.N.-M.); kondo@nihs.go.jp (K.K.) \\ * Correspondence: kwaka@fujita-hu.ac.jp; Tel.: +81-562-93-2000 (ext. 3253); Fax: +81-562-93-9847
}

check for

updates

Citation: Tanaka, H.; Ito, S.; Ojika, M.; Nishimaki-Mogami, T.; Kondo, K.; Wakamatsu, K. The Oxidation of Equol by Tyrosinase Produces a Unique Di-ortho-Quinone: Possible Implications for Melanocyte Toxicity. Int. J. Mol. Sci. 2021, 22, 9145. https://doi.org/10.3390/ ijms22179145

Academic Editor: Marian Valko

Received: 22 July 2021

Accepted: 23 August 2021

Published: 24 August 2021

Publisher's Note: MDPI stays neutral with regard to jurisdictional claims in published maps and institutional affiliations.

Copyright: (c) 2021 by the authors. Licensee MDPI, Basel, Switzerland. This article is an open access article distributed under the terms and conditions of the Creative Commons Attribution (CC BY) license (https:// creativecommons.org/licenses/by/ $4.0 /)$.
Abstract: Equol (7-hydroxy-3-(4'-hydroxyphenyl)-chroman, EQ), one of the major intestinally derived metabolites of daidzein, the principal isoflavane found in soybeans and most soy foods, has recently attracted increased interest as a health-beneficial compound for estrogen-dependent diseases. However, based on its structure with two $p$-substituted phenols, this study aimed to examine whether EQ is a substrate for tyrosinase and whether it produces $o$-quinone metabolites that are highly cytotoxic to melanocyte. First, the tyrosinase-catalyzed oxidation of EQ was performed, which yielded three EQ-quinones. They were identified after being reduced to their corresponding catechols with $\mathrm{NaBH}_{4}$ or L-ascorbic acid. The binding of the EQ-quinones to $\mathrm{N}$-acetyl-L-cysteine (NAC), glutathione (GSH), and bovine serum albumin via their cysteine residues was then examined. NAC and GSH afforded two mono-adducts and one di-adduct, which were identified by NMR and MS analysis. It was also found that EQ was oxidized to EQ-di-quinone in cells expressing human tyrosinase. Finally, it was confirmed that the EQ-oligomer, the EQ oxidation product, exerted potent pro-oxidant activity by oxidizing GSH to the oxidized GSSG and concomitantly producing $\mathrm{H}_{2} \mathrm{O}_{2}$. These results suggest that EQ-quinones could be cytotoxic to melanocytes due to their binding to cellular proteins.

Keywords: anti-aging; antioxidant; melanocyte toxicity; ortho-quinone; equol

\section{Introduction}

Equol (7-hydroxy-3-(4'-hydroxyphenyl)-chroman, EQ 1) has recently attracted increased interest as a health-beneficial compound for estrogen-dependent diseases [1,2]. Equol 1 was the first isoflavanoid identified from fluids extracted from the urine of pregnant mares in 1932 [3]. In 1982, EQ 1 was first detected in human urine and blood as a non-steroidal estrogenic compound [4] and was found in high concentrations in the urine of about $40 \%$ of adults who consumed soy foods [5]. EQ 1 is one of the main metabolites of daidzein and is an isoflavane phenolic compound with a non-planar structure that is optically active with an asymmetric carbon atom at the $C 3$ position giving rise to $(R)-(+)-$ and $(S)-(-)$-EQ enantiomers (Figure 1). Only (S)-(-)-EQ 1 has been detected as a product of bacterial daidzein conversion [6-8]. EQ 1 shows an anti-androgenic activity by binding to and sequestering $5 \alpha$-dihydrotestosterone [9]. In addition, EQ 1 has been shown to have antioxidant activity $[10,11]$ and binds to estrogen receptors to show a stronger estrogenic activity than that of any other isoflavone or isoflavone-derived metabolite $[8,12]$. 


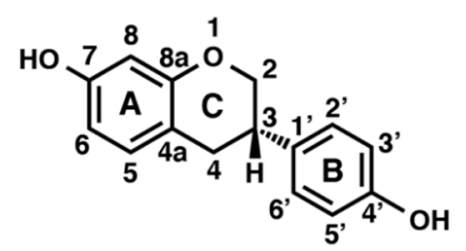

(S)-(-)-Equol (EQ, 1)<smiles>Oc1ccc2c(c1)OC[C@H](c1ccc(O)c(O)c1)C2</smiles>

Equol-catechol-A (3'-OH-EQ, 2)<smiles>Cc1cc2c(cc1O)C[C@@H](c1ccc(O)cc1)CO2</smiles>

Equol-catechol-B (6-OH-EQ, 3)<smiles>C=CC(C)C</smiles>

Equol-catechol-C (6,3'-DIOH-EQ, 4)
Tyrosinase<smiles>Oc1ccc2c(c1)OCCO2</smiles>

Equol-quinone-A<smiles>[B]CCc1ccc2c(c1)CC[C@H](c1cc(O)c(O)c(S)c1)C2</smiles>

Mono-adduct-A

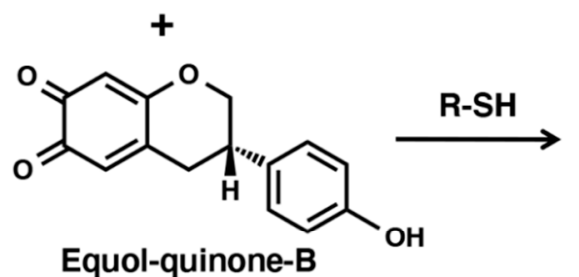

Equol-quinone-B<smiles>Oc1ccc([C@H]2COc3cc(O)c(O)c(S)c3C2)cc1</smiles>

Mono-adduct-B<smiles>O=C1C=CC(C=C2C=C([C@H]3C=CC(=O)C(=O)C3)C=CC2=O)=CC1=O</smiles>

Equol-quinone-C

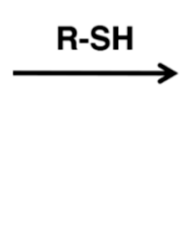<smiles>Oc1cc([C@H]2COc3cc(O)c(O)c(Br)c3C2)cc(S)c1O</smiles>

Figure 1. Scheme showing the tyrosinase-catalyzed oxidation of $(S)-(-)$-equol $(E Q, 1)$ in the absence or presence of a thiol. The oxidation of (S)-(-)-EQ 1 gives EQ-quinone-A and -B as immediate products, which are then oxidized to EQ-quinone-C. EQ-quinones are reduced by $\mathrm{NaBH}_{4}$ or L-ascorbic acid (AA) to form EQ-catechols, as shown by [H]. The tyrosinase-catalyzed oxidation of (S)-(-)-EQ 1 in the presence of a thiol, NAC, CySH, or GSH affords two mono-adducts and one di-adduct.

Rhododendrol (4-(4-hydroxyphenyl)-2-butanol, RD) is a skin-whitening ingredient that was added to cosmetics by a cosmetic company in Japan. In July 2013, cosmetics containing RD were recalled because a considerable number of consumers developed leukoderma on their faces, necks, and hands [13]. RD was shown to exert melanocyte toxicity via a tyrosinase-dependent mechanism [14]. Ito et al. $[15,16]$ reported that the oxidation of RD by mushroom tyrosinase produced RD-quinone as an intermediate product, which leads to the binding of cellular thiol proteins as well as non-protein thiols, glutathione $(\mathrm{GSH})$, and cysteine (CySH). Furthermore, Ito et al. [16,17] demonstrated that the RDoligomer derived from RD-quinone exerts a potent pro-oxidant activity by oxidizing GSH and other cellular antioxidants and by concomitantly producing $\mathrm{H}_{2} \mathrm{O}_{2}$.

trans-Resveratrol (3,5,4'-trihydroxy-trans-stilbene, RES) is a naturally occurring polyphenol that is well known for its antioxidant, antiplatelet, anti-inflammatory, anti-aging, anticancer, anti-diabetic, cardioprotective, and cancer chemopreventive properties as well as its neuroprotective properties $[18,19]$. RES is generally considered a good inhibitor of tyrosinase rather than a substrate [20]. For example, Park et al. showed that RES strongly inhibits mushroom tyrosinase [21]. RES has a $p$-substituted phenol structure similar to that of RD and was found to be a good substrate for tyrosinase and was oxidized to produce a highly reactive $o$-quinone form [22]. This RES-quinone decayed rapidly to produce an oligomer that exhibited a pro-oxidant activity [22]. Based on these results, Ito et al. [22] suggested that the cosmetic use of RES should be considered with caution. Indeed, toxicity and adverse effects were reported following the consumption of RES. Therefore, extensive future studies on the long-term effects, as well as the in vivo adverse effects, of RES supplementation in humans are needed [23]. 
As mentioned above, the various beneficial health properties of EQ 1 against a variety of disorders, including heart and vascular diseases, osteoporosis, and hormone-dependent cancers (such as those of the breast and prostate) have also been reported [24-26]. However, EQ 1 has the same $p$-substituted phenol structure as that of RD and RES. EQ 1 also has a bicyclic chroman structure similar to a metabolic intermediate of RD, RD-cyclic catechol [27]. Thus, EQ 1 is expected to have chemical and biochemical properties similar to those of RD and RES. Nevertheless, it has not yet been reported whether EQ 1 acts as a substrate for tyrosinase as does RD and RES. However, since tyrosinase has recently been adopted for efficient isoflavone hydroxylation in recombinant strains [28] and EQ 1 has a unique structure that has two phenolic groups, the oxidation of EQ $\mathbf{1}$ by tyrosinase is expected to give rise to EQ-quinone-A and - $\mathrm{B}$ as intermediates, which are then oxidized to EQ-quinone$\mathrm{C}$ (Figure 1). These EQ-quinones can be identified after being reduced with $\mathrm{NaBH}_{4}$ or L-ascorbic acid (AA) to their corresponding catechols, as was performed to identify the $o$-quinones of RD and RES [22,27]. These EQ-quinones are also expected to react with $\mathrm{N}$-acetyl-L-cysteine (NAC), CySH, GSH, and bovine serum albumin (BSA) through their $\mathrm{CySH}$ residues to form two mono-adducts and one di-adduct.

In order to determine whether EQ $\mathbf{1}$ is a substrate for tyrosinase and whether it produces toxic $o$-quinone metabolites, EQ 1 was oxidized with tyrosinase, and it was determined whether EQ 1 binds to small and protein thiols. Then, the metabolism of EQ 1 was also examined in tyrosinase-transfected cells. Finally, it was shown that the EQ oxidation product, the EQ-oligomer, derived from EQ-quinone, exerts potent prooxidant activity by oxidizing GSH to the oxidized glutathione (GSSG) and concomitantly producing $\mathrm{H}_{2} \mathrm{O}_{2}$.

\section{Results}

\subsection{Tyrosinase-Catalyzed Oxidation of EQ 1 Produces EQ-Quinones}

The oxidation of $100 \mu \mathrm{M}$ EQ 1 by mushroom tyrosinase $(50 \mathrm{U} / \mathrm{mL})$ was carried out at $37^{\circ} \mathrm{C}$ in $50 \mathrm{mM}$ sodium phosphate buffer at $\mathrm{pH} 6.8$. UV/visible spectral changes were followed for $60 \mathrm{~min}$, which showed the rapid production of a quinoid chromophore with absorption at around 400-450 nm (Figure 2a). To slow down the reaction in order to determine the absorption maximum, the oxidation was then carried out at $\mathrm{pH} 5.3$ [22,29], which showed a clear absorption maximum at $420 \mathrm{~nm}$ after 10-30 min reaction (Figure 2b).

As the UV/visible spectral changes appeared to be complex, the oxidation at $\mathrm{pH} 5.3$ using high-performance liquid chromatography (HPLC) was performed. As most of the products appeared to be unstable quinones, they were converted to more stable catechols by reducing them with $10 \% \mathrm{NaBH}_{4}$. As shown in Figure $2 \mathrm{c}$, the oxidation did not proceed quickly at the beginning but then started to proceed faster. EQ 1 was consumed within $15 \mathrm{~min}$, giving new compounds with retention times in HPLC of 7.0, 9.9, and $12.0 \mathrm{~min}$ (EQ 1 appeared at $19.4 \mathrm{~min}$ ). The three EQ-catechols were given the names EQ-catechol-A 2, EQ-catechol-B 3, and EQ-catechol-C 4 according to their decreasing order of retention times. The production of three EQ-catechols was expected for the two possible mono-catechol isomers and the one possible di-catechol. The isolation and identification of those three EQ-catechols is described later.

The production of the three possible EQ-catechols during the tyrosinase-catalyzed oxidation was further confirmed by oxidizing $100 \mu \mathrm{M}$ EQ 1 in the presence of $10 \mathrm{~mol}$ eq. AA $(1000 \mu \mathrm{M})$ at $\mathrm{pH}$ 5.3. As shown in Figure 2d, HPLC analysis of the reaction mixtures showed a rapid decrease in EQ 1 in 2 min, giving the three EQ-catechols, which were then oxidized to EQ-quinones after all of the AA was consumed through a redox exchange after ca. $30 \mathrm{~min}$ reaction. The time course shown in Figure $2 \mathrm{~d}$ indicates that EQ-catechol-C 4 was produced from EQ-catechol-A 2 and EQ-catechol-B 3, which suggests that EQ-catechol-C 4 is most likely a di-catechol. 
a)

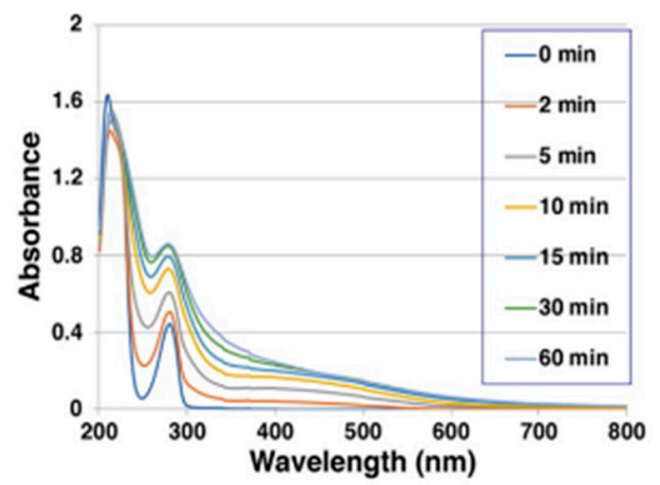

c)

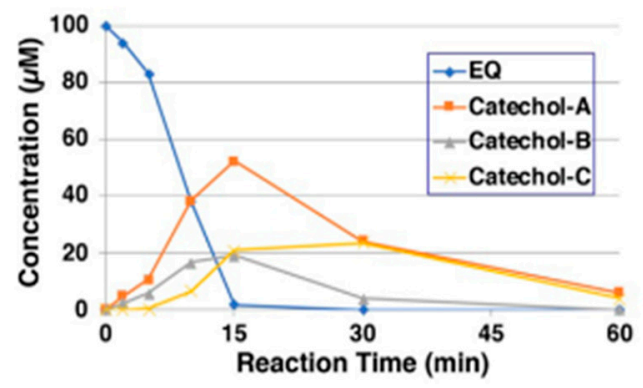

b)

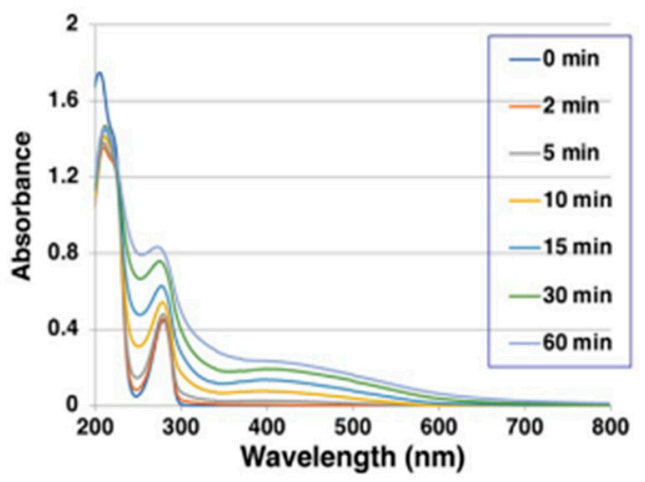

d)

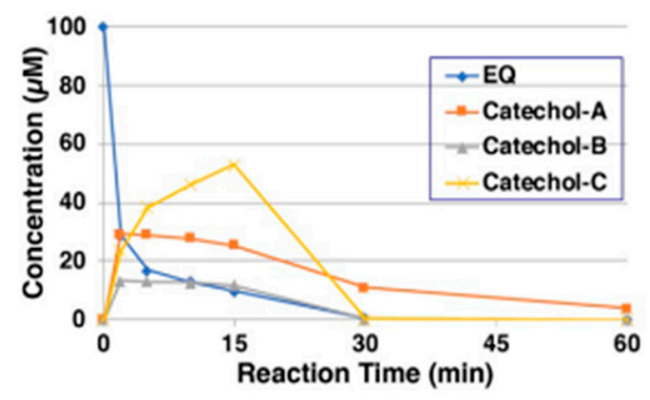

Figure 2. Time course of the tyrosinase-catalyzed oxidation of EQ 1 and HPLC analyses of reaction products. (a) UV/visible spectral changes of EQ 1 at pH 6.8; (b) UV/visible spectral changes of EQ 1 at pH 5.3; (c) HPLC analysis following the tyrosinase-catalyzed oxidation of EQ 1 at $\mathrm{pH}$ 5.3, the reaction being stopped by the addition of $\mathrm{NaBH}_{4}$, followed by $\mathrm{HClO}_{4}$; (d) HPLC analysis following the tyrosinase-catalyzed oxidation of EQ $\mathbf{1}$ at pH 5.3 in the presence of 10 mol eq. AA, the reaction being stopped by the addition of $\mathrm{HClO}_{4}$. Data for $(\mathbf{a}, \mathbf{b})$ were obtained from single experiments, but reproducibility was confirmed for each experiment. Data for $(\mathbf{c}, \mathbf{d})$ were obtained from averages of two independent experiments.

To confirm the structure of those three EQ-catechols, they were prepared by the tyrosinase-catalyzed oxidation of $1 \mathrm{mM}$ EQ 1 in the presence of 10 mol eq. AA at pH 6.8 for $20 \mathrm{~min}$ at $37^{\circ} \mathrm{C}$ [22]. The three compounds were assigned as $3^{\prime}$-hydroxy-EQ 2 (EQcatechol-A; 25\% yield), 6-hydroxy-EQ 3 (EQ-catechol-B; 12\% yield), and 6,3'-dihydroxy-EQ 4 (EQ-catechol-C; $25 \%$ yield) on the basis of ${ }^{1} \mathrm{H}$ nuclear magnetic resonance $\left({ }^{1} \mathrm{H}-\mathrm{NMR}\right)$ and high-resolution electrospray ionization (ESI)-time of flight mass spectrometry (TOF MS) spectra. The assignment of the structures of 3'-hydroxy-EQ 2 with a mono-hydroxy group at the $3^{\prime}$ position in the B-ring of EQ 1, 6-hydroxy-EQ 3 with a mono-hydroxy group at the 6 position in the A-ring of EQ 1, and 6,3'-dihydroxy-EQ 4 with di-hydroxy groups at the 6 and $3^{\prime}$ positions in the A- and B-rings of EQ 1 was carried out via a comparison with the structural data of EQ 1 previously reported [30-33] (Figure 1, Figure S1a-d, and Table S1).

\subsection{Reaction of EQ-Quinones with Non-Protein Thiol Compounds Produces Mono-} and Di-adducts

Next, it was investigated whether EQ-quinone(s) could bind to thiol compounds $[15,22,27,29]$. NAC was selected as a model of biologically important thiol compounds. NAC adducts can be extracted with organic solvents and are easily characterized by NMR and MS. Then, $100 \mu \mathrm{M}$ EQ 1 was oxidized with tyrosinase $(50 \mathrm{U} / \mathrm{mL})$ in the presence of $300 \mu \mathrm{M} \mathrm{NAC}$ at $\mathrm{pH}$ 6.8. HPLC analysis showed little reaction until $30 \mathrm{~min}$, after which the reaction began and produced four major compounds with retention times of 6.1, 6.6, 7.1, and $7.7 \mathrm{~min}$ for two di- and two mono-adducts, respectively (EQ 1 appeared at $19.7 \mathrm{~min}$; Figure 3a). The assignment of di- and mono-adducts is tentative based on the order of retention times; compounds with more thiol addition usually have 
shorter retention times for hydrophobic catechols [22,29]. Structural assignments of those compounds are described later.

a)

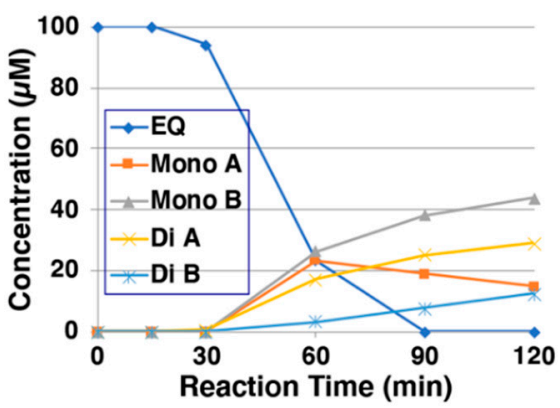

b)

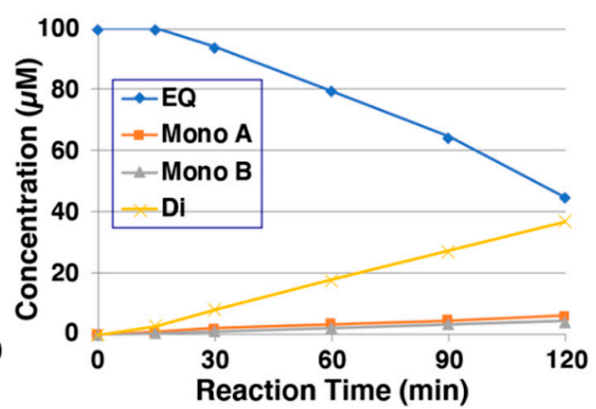

c)

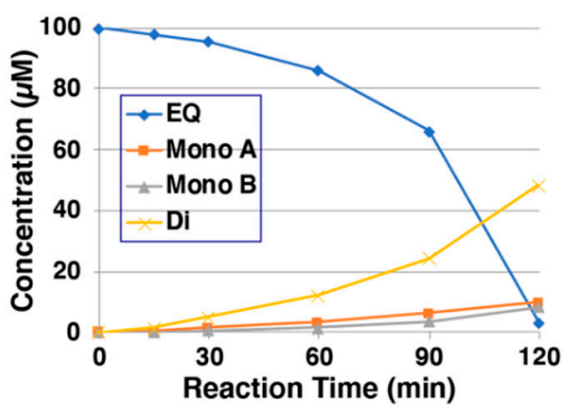

Figure 3. Time course of the tyrosinase-catalyzed oxidation of EQ 1 in the presence of NAC, CySH, or GSH. (a) HPLC analysis following the tyrosinase-catalyzed oxidation of EQ 1 in the presence of 3 mol eq. NAC at pH 6.8; (b) HPLC analysis following the tyrosinase-catalyzed oxidation of EQ 1 in the presence of 3 mol eq. CySH at pH 6.8; (c) HPLC analysis following the tyrosinase-catalyzed oxidation of EQ 1 in the presence of 3 mol eq. GSH at pH 6.8. The reaction was stopped by the addition of $\mathrm{HClO}_{4}$. Data were obtained from averages of two independent experiments. Mono-A, mono-B, di-A, and di-B had retention times with decreasing order in each thiol adduct.

We then examined how CySH and GSH react with EQ-quinone(s). In order to do this, $100 \mu \mathrm{M}$ EQ 1 was oxidized with tyrosinase in the presence of $3 \mathrm{~mol}$ eq. CySH or GSH at $\mathrm{pH}$ 6.8. The reaction with $\mathrm{CySH}$ (Figure $3 \mathrm{~b}$ ) produced three major compounds at 5.9, 6.6, and $6.9 \mathrm{~min}$. They were tentatively assigned one di-adduct and two mono-adducts. Similarly, the reaction with GSH (Figure 3c) showed the production of three major compounds at 5.8, 6.2 , and $6.4 \mathrm{~min}$. They were tentatively assigned one di-adduct and two mono-adducts.

To confirm the structures of the NAC adducts, tyrosinase-catalyzed oxidation of EQ $1(1 \mathrm{mM})$ was carried out in the presence of NAC. However, the reaction did not proceed for several $\mathrm{h}$ because of the inhibition of tyrosinase activity by thiols. Therefore, $3^{\prime}$-hydroxy-EQ $2(100 \mu \mathrm{M})$ was added as a catalyst to accelerate the oxidation, which then proceeded rapidly and produced two major compounds, which were isolated by preparative HPLC. ${ }^{1} \mathrm{H}$ NMR analysis of the product with the longer retention time gave two meta-oriented aromatic protons on one benzene ring and three 1,2,4-oriented protons on another benzene ring, along with one NAC moiety (Figures S3a and S4a, and Table S1). Mass data indicated the structure of the mono-adduct of NAC (see Section 4). ${ }^{1} \mathrm{H}$ NMR analysis of the product with a shorter retention time gave an isolated aromatic proton and two 1,3-oriented aromatic protons, along with two NAC moieties (Figures S3b and S4b, and Table S1). Mass data indicated the structure of di-adducts of NAC (see Section 4). Based on those NMR and MS data, the structures $5^{\prime}$-monoNAC-3'-hydroxy-EQ $5(12 \%)$ and 5,5'diNAC-6,3'-dihydroxy-EQ 6 (5\%) were assigned to the adducts with a longer and a shorter retention time, respectively (Figure 1). Those mono-adduct and di-adducts that were identified to correspond to Mono-A and Di-A, respectively, are shown in Figure 3a. The structure of Mono-B could not be determined because it had a low yield. It was tentatively assigned as a mono-adduct, but the production of Mono-B increased continuously, so it could be a di-adduct.

The isolation of CySH adducts turned out to be difficult because of their instability. On the other hand, GSH adducts could be isolated using preparative HPLC. 3'-HydroxyEQ 2 was used as a source of EQ-quinone. Two GSH adducts were isolated and were subjected to NMR and MS analyses (see Section 4). A slower-eluting adduct was identified as 5'-monoGS-3'-EQ 7 (59\%; Figure 1, Figures S5a,b, S5d-f and S6a, and Table S2) and a faster-eluting adduct was 5,5'-diGS-6,3'-dihydroxy-EQ 8 (3\%) (Figures S5c and S6b). 


\subsection{Reaction of $E Q-Q u i n o n e s$ with $B S A$}

In addition, we examined how EQ-quinone reacted with BSA. BSA, which contains one $\mathrm{CySH}$ residue in addition to 17 cystine residues, was selected as a representative thiol protein because it is known to react with various o-quinones [15,29,34]. To confirm the possible involvement of $\mathrm{CySH}$ in the binding of BSA to EQ-quinone, $100 \mu \mathrm{M} 3^{\prime}$ hydroxy-EQ 2 was oxidized by tyrosinase in the presence of 3 mol eq. $N$-ethylmaleimide (NEM)-modified BSA in which the CySH residue was modified with NEM. The NEM-BSA that reacted with EQ-quinone(s) with an absorption of 0.39 at $400 \mathrm{~nm}$ was approximately 2.3 times greater than that with native BSA with an absorption of 0.16 (Figure 4) and also greater than that without protein added $(0.23$ at $400 \mathrm{~nm}$; Figure 1). The production of a quinoid chromophore between the amino groups of NEM-BSA and EQ-quinone may have caused this large absorption from NEM-modified BSA. These results indicate that the majority of EQ-quinones can bind to BSA through CySH residues as in the case of RES-quinone [22].

a)

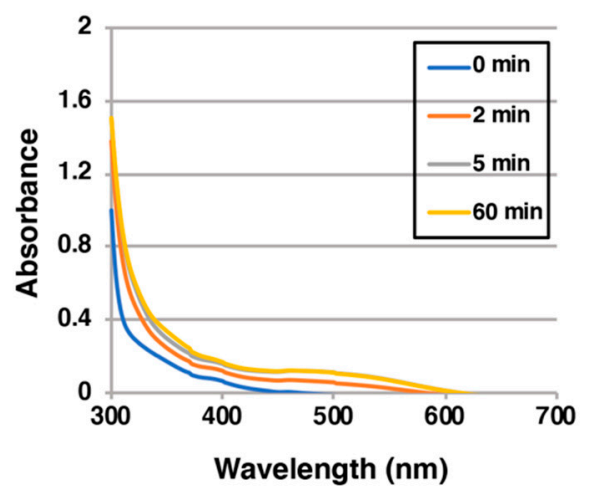

b)

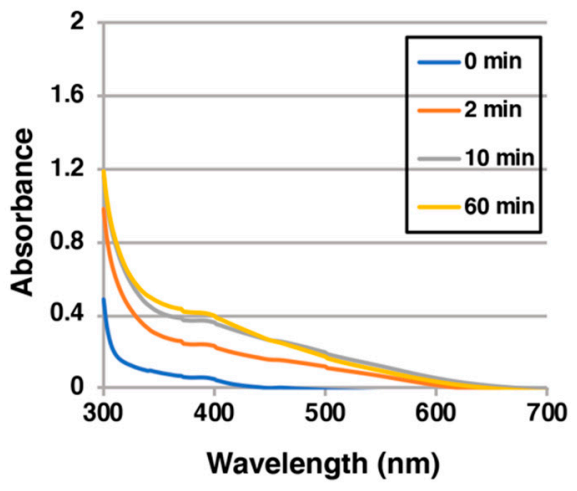

Figure 4. Time course of the tyrosinase-catalyzed oxidation of 3'-hydroxy-EQ 2 in the presence of BSA. (a) UV/visible spectral changes of 3'-hydroxy-EQ 2 in the presence of 3 mol eq. BSA (containing 0.90 mol eq. SH group) at $\mathrm{pH} 6.8$; (b) UV/visible spectral changes of 3'-hydroxy-EQ 2 in the presence of $3 \mathrm{~mol}$ eq. NEM-modified BSA at $\mathrm{pH}$ 6.8. Data were obtained from single experiments, but reproducibility was confirmed for each experiment.

\subsection{Metabolism of EQ 1 in Tyrosinase-Transfected Cells}

We next investigated whether EQ $\mathbf{1}$ is in fact oxidized to EQ-quinones in cells expressing human tyrosinase, and whether the binding of EQ-quinone to cellular thiols occurs. Ectopic expressions of the human tyrosinase gene in non-melanogenic cells have been reported [35,36]. The human tyrosinase gene in 293T cells, which are widely used for highlevel expression of proteins from plasmid vectors, was transiently transfected. Twenty-four hours after transfection, the cells were exposed to EQ 1 for $2 \mathrm{~h}$. The $0.2 \mathrm{mM}$ concentration of EQ 1 is the maximum non-toxic dose. As shown in Figure 5a, EQ 1 was taken up into the tyrosinase-transfected T293 cells and was metabolized in a dose-dependent manner to DiCys-EQ-catechol and DiGS-EQ-catechol. Those di-adducts were the major metabolites, while mono-adducts were only minor products according to the HPLC analysis. DiGS-EQcatechol was identified as 5,5'-diGS-6,3'-dihydroxy-EQ 8 (Figure 1, Figures S5c and S6b). Those metabolites were then released into the medium (Figure 5b). The EQ 1 content in medium exposed to $100 \mu \mathrm{M}$ EQ 1 was $70 \mu \mathrm{M}$, which contained $0.60 \mu \mathrm{M}$ DiCys-EQ-catechol and $0.66 \mu \mathrm{M}$ DiGS-EQ-catechol 8. Thus, about $2 \%$ of the EQ 1 present in the medium was metabolized in cells and released to the medium as Cys and GSH adducts during the $2 \mathrm{~h}$ incubation period. Notably, the adducts that formed in the tyrosinase-transfected cells are di-adducts but not mono-adducts. This is consistent with the predominant production of di-adducts in the biochemical experiments (Figure 3b,c). 
a)

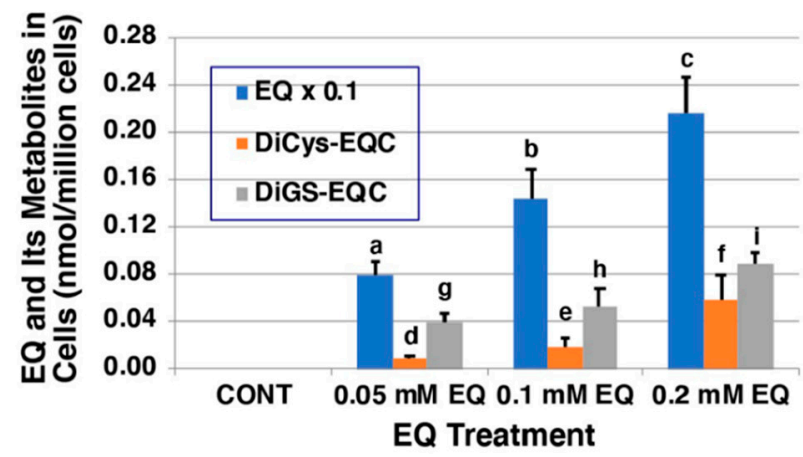

b)

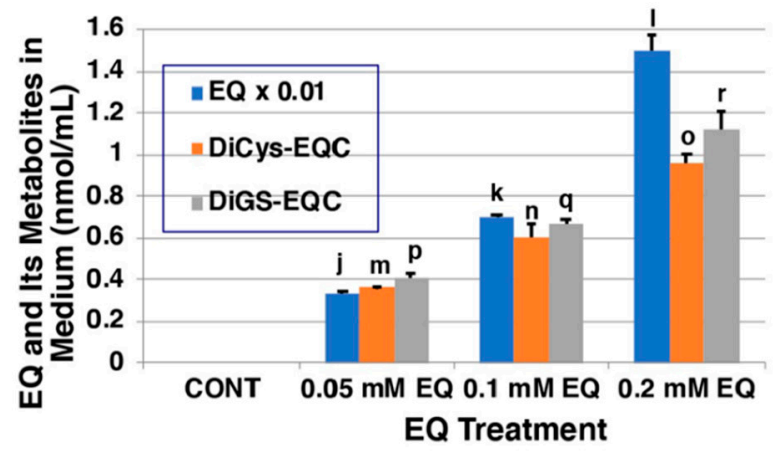

Figure 5. Metabolism of EQ 1 in cells transfected with human tyrosinase yielding di-adducts of CySH and GSH (a) in the cells; $(\mathbf{b})$ in the medium. The data are mean \pm SD from triplicate dishes. Statistically significant differences: $p<0.05$ (a-b; b-c; d-f; e-f; h-i), $p<0.01$ (a-c; g-i; n-o), $p<0.001$ (j-k; k-1; j-l; m-n; m-o; p-q; q-r; p-r). Non-significant differences: g-h $(p>0.1) ; \mathrm{d}-\mathrm{e}(p>0.05)$. The statistical significance of the differences was determined by Student's $t$-test (two-tailed).

\subsection{EQ-Oligomer Oxidizes GSH to GSSG (Pro-Oxidant Activity)}

Previously, Ito et al. [29] reported that RD oligomers prepared by the tyrosinasecatalyzed oxidation of RD have a strong pro-oxidant activity. In another study, Ito et al. [22] reported that the pro-oxidant activity of RES-oligomers also contributes to cytotoxicity, although it is weaker than that of RD oligomers. Therefore, in the present study, it was investigated whether the EQ-oligomer, which is an oligomer oxidation product of EQ 1, has a pro-oxidant activity. EQ-oligomers were prepared by oxidizing $1 \mathrm{mM}$ EQ 1 with tyrosinase $(100 \mathrm{U} / \mathrm{mL})$ for $120 \mathrm{~min}$ at $\mathrm{pH}$ 7.4. The EQ-oligomer was exposed to $1 \mathrm{~mol}$ eq. GSH and was followed for up to $60 \mathrm{~min}$. Then, the remaining levels of GSH and GSSG were analyzed using 3,5-di-tert.-butyl-1,2-benzoquinone (DBBQ) with a specific HPLC method $[17,37]$. GSH levels were reduced by ca. $60 \%$ during the $60 \mathrm{~min}$ incubation period with EQ-oligomers (Figure 6a). Most of the GSH was oxidized to GSSG.

a)

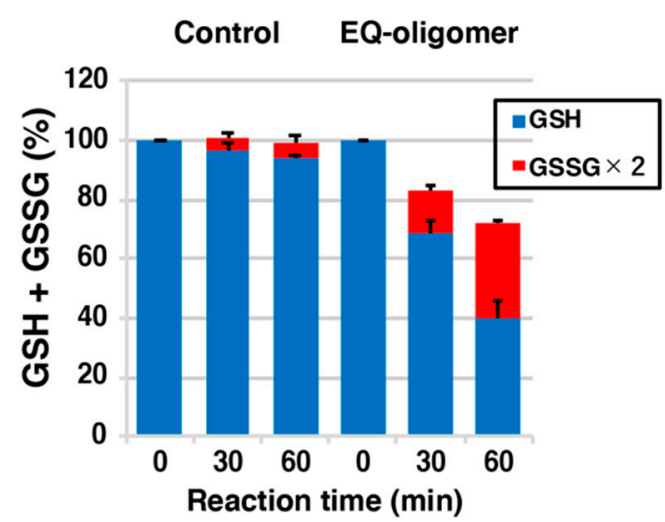

b)

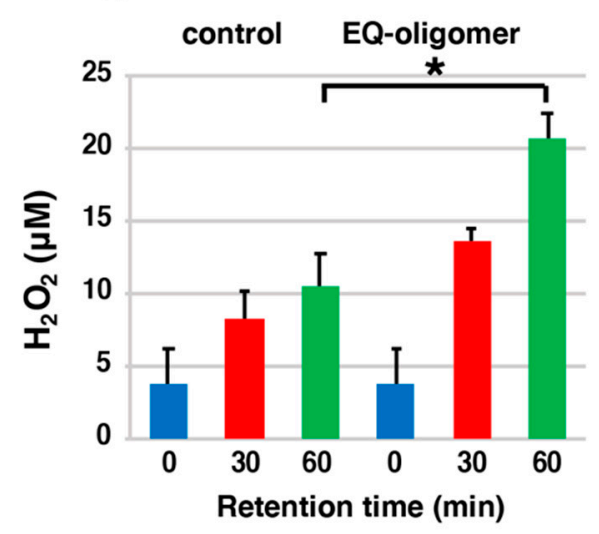

Figure 6. Oxidation of GSH and production of $\mathrm{H}_{2} \mathrm{O}_{2}$ by the EQ-oligomer. (a) The consumption of GSH and the production of GSSG from 1 mol eq. GSH; (b) the production of $\mathrm{H}_{2} \mathrm{O}_{2}$ before and 30 and $60 \mathrm{~min}$ after the oxidation of GSH. The data are mean \pm SEM from 3 experiments $\left({ }^{*} p<0.05\right)$.

Next, we examined whether $\mathrm{H}_{2} \mathrm{O}_{2}$ was produced during the oxidation of $\mathrm{GSH}$ by these oligomers. As shown in the Figure $6 \mathrm{~b}, 21 \mu \mathrm{M} \mathrm{H}_{2} \mathrm{O}_{2}$ was produced from the EQ-oligomer during the $60 \mathrm{~min}$ reaction with GSH $(11 \mu \mathrm{M}$ in the control).

\section{Discussion}

Topical application of EQ 1 is generally considered to be more beneficial than harmful to the skin [12]. Niwa et al. [30] recently reported that racemic EQ 1 inhibits mushroom 
tyrosinase in vitro. It is also known that daidzein and EQ 1 decrease the expression of tyrosinase, tyrosinase-related protein-1 (TRP-1), and tyrosinase-related protein-2 (TRP2 ), thereby blocking melanin production in $\alpha$-MSH-stimulated B16 melanoma cells [38]. However, in this study, it was shown that tyrosinase can effectively oxidize EQ 1 to produce two EQs with a mono-quinone skeleton (A and $B$ ) and one EQ with a di-quinone (C), all of which are highly reactive. The high reactivity is illustrated by their rapid decay (Figure 2) and the production of 3'-hydroxy-EQ 2 and 6-hydroxy-EQ 3 as mono-catechols and 6,3'dihydroxy-EQ 4 as a di-catechol (Figure 1). EQ 1 is well known as a substrate for P450 enzymes. Rüfer et al. [33] reported that the main metabolites of ( \pm )-EQ 1 in rat and human microsomal metabolisms are 3'-hydroxy-EQ 2 and 6-hydroxy-EQ 3, but 6,3'-dihydroxy-EQ 4 was not identified. On the other hand, DiCys-EQ-catechol and DiGS-EQ-catechol 8 as the major metabolites of EQ 1 in human tyrosinase-transfected cells were identified. These results show that those metabolites are produced through EQ-quinone-C (Figure 1).

The reaction of EQ 1 with NAC in the presence of tyrosinase afforded $5^{\prime}$-monoNAC$3^{\prime}$-hydroxy-EQ 5 and 5,5'-diNAC-6,3'-dihydroxy-EQ 6. Although the isolation of the CySH adducts was difficult because of their instability, two GSH adducts, $5^{\prime}$-monoGS$3^{\prime}$-EQ 7 and 5,5'-diGS-6,3'-dihydroxy-EQ 8, using 3'-hydroxy-EQ 2 as a source of EQquinone, were isolated. These results suggest that EQ-quinone could be cytotoxic to melanocytes due to the binding of EQ-quinones to thiol proteins. Although not as potent as the RD-oligomer [17], the pro-oxidant activity of the EQ-oligomer may contribute to its higher cytotoxicity than the RES-oligomer according to the reduction in GSH levels [22]. Similarly, the production of $\mathrm{H}_{2} \mathrm{O}_{2}$ from the EQ-oligomer was less than that from the RDoligomer [17] but more than that from the RES-oligomer [22]. We also examined whether EQ 1 was oxidized to EQ-quinone in T293 cells transfected with human tyrosinase. EQ 1 was metabolized in a dose-dependent manner to DiCys-EQ-catechol and DiGS-EQ-catechol 8 as major metabolites. Those metabolites were then released into the medium, and about $2 \%$ of the EQ 1 present in the medium was metabolized in the cells and released into the medium as Cys and GSH adducts during the $2 \mathrm{~h}$ incubation. The predominant production of di-adducts is consistent with the biochemical experiments. As EQ $\mathbf{1}$ is defined as a di-phenol with two $p$-substituted phenol structures, it was confirmed that EQ 1 can be oxidized to the corresponding di-o-quinone, indicating that it is a good substrate for not only mushroom tyrosinase but also human tyrosinase. These situations are similar to those observed with RD and RES being a good inhibitor as well as a good substrate of tyrosinase [14-16,22,27], including human tyrosinase [39]. Di-o-quinone generated by tyrosinase oxidation of EQ 1 bound to thiols to form di-adducts, which was confirmed in the tyrosinase-transfected cells.

In this study, mono- and di-adducts of EQ-quinones with thiol compounds in the presence of tyrosinase were obtained. As far as we are aware, this is the first study in which di-phenol produced di-o-quinone, and both were involved in adduct formation. This high reactivity of EQ-quinones would lead to cytotoxicity by inactivating the $\mathrm{SH}$ enzymes and by unfolding $\mathrm{SH}$ proteins causing endoplasmic reticulum (ER) stress. In this connection, it is known that RD induces the ER stress response and apoptosis in melanocytes [14,40].

\section{Materials and Methods}

\subsection{Materials}

(S)-(-)-Equol (7-hydroxy-3-(4'-hydroxyphenyl)-chroman) (EQ) 1 was purchased from Daicel Corporation (Osaka, Japan). Tyrosinase (from mushrooms, specific activity $2687 \mathrm{U} / \mathrm{mg}$ ), L-cysteine (CySH), reduced glutathione (GSH), oxidized glutathione (GSSG), $\mathrm{N}$-acetyl-L-cysteine (NAC), bovine serum albumin (BSA), horseradish peroxidase, Dulbecco's Modified Eagle's Medium (DMEM) containing 10\% fetal bovine serum, and Ampliflu $^{\mathrm{TM}}$ Red reagent (10-acetyl-3,7-dihydroxyphenoxazine) were purchased from SigmaAldrich (St. Louis, MO, USA). $\mathrm{H}_{2} \mathrm{O}_{2}$ was purchased from Mitsubishi Gas Chemical Co., Ltd. (Tokyo, Japan). Perchloric acid $\left(\mathrm{HClO}_{4}\right)$ was purchased from Katayama Chemical Industries Co., Ltd. (Osaka, Japan). Formic acid (HCOOH), ethanol (HPLC grade), methanol (HPLC 
grade), ethyl acetate, $\mathrm{NaBH}_{4}$, 3,5-di-tert.-butyl-1,2-benzoquinone (DBBQ), L-ascorbic acid (AA), and 2-mercaptoethanol (thioglycol) were from FUJIFILM Wako Pure Chemical Corporation (Osaka, Japan). The highest purity Milli-Q water (Milli-Q Advantage, Merck Millipore Co., Tokyo, Japan) was used throughout this study to avoid contamination with metal ions. N-ethylmaleimide (NEM) was from Tokyo Chemical Industries (Tokyo, Japan). NEM-modified BSA was prepared by reacting $0.01 \mathrm{mmol}$ BSA with $0.3 \mathrm{mmol}$ NEM in $50 \mathrm{mM}$ sodium phosphate buffer, $\mathrm{pH} 6.8(10 \mathrm{~mL})$ at $37^{\circ} \mathrm{C}$ for $60 \mathrm{~min}$. The NEM-modified BSA was mixed with $40 \mathrm{~mL}$ cold ethanol and precipitated by centrifugation, washed three times with $20 \mathrm{~mL}$ cold ethanol, and dissolved in the $\mathrm{pH} 6.8$ buffer. The concentration of NEM-modified BSA was estimated from previous data to be $0.51 \mathrm{mM}$ based on UV spectrophotometry at $280 \mathrm{~nm}$.

\subsection{Instruments}

A HPLC system was used to follow the course of tyrosinase oxidation. It comprised an analytical UV/VIS detector, a JASCO pump (JASCO Co., Tokyo, Japan), a C18 column (Capcell Pak MG; $4.6 \times 250 \mathrm{~mm}$; 5 m particle size, Osaka Soda, Osaka, Japan), and a JASCO UV/visible detector (JASCO Co., Tokyo, Japan). The mobile phase was $0.4 \mathrm{M}$ $\mathrm{HCOOH}$ : methanol, 60:40 (v/v). Analyses were performed at $50{ }^{\circ} \mathrm{C}$ at a flow rate of $0.7 \mathrm{~mL} / \mathrm{min}$. For preparative separation, a C18 preparative column (Capcell Pak MG; $20 \times 250 \mathrm{~mm} ; 5 \mu \mathrm{m}$ particle size, Osaka Soda, Osaka, Japan) was used at a flow rate of $7.0 \mathrm{~mL} / \mathrm{min}$ with the mobile phase $(0.4 \mathrm{M} \mathrm{HCOOH}$ : methanol, $50: 50(v / v))$ at $45^{\circ} \mathrm{C}$. A Shiseido electrochemical detector (Shiseido, Tokyo, Japan) was also used to analyze low concentrations of metabolites, as electrochemical detection is $>10$-times more sensitive than $\mathrm{UV} /$ visible detection.

Nuclear magnetic resonance (NMR, $400 \mathrm{MHz}$ for ${ }^{1} \mathrm{H}$ ) spectra were obtained using a Bruker AVANCE 400 spectrometer (Billerica, MA, USA). High-resolution mass spectra were obtained using a 6220 TOF mass spectrometer (mode: electrospray ionization-timeof-flight, negative; ESI(-) or positive; ESI (+)-TOF) (Agilent Technologies, Santa Clara, CA, USA).

For measurements of $\mathrm{H}_{2} \mathrm{O}_{2}$, the maximum absorption wavelength of $571 \mathrm{~nm}$ possessed by red fluorescent resorufin in which Ampliflu ${ }^{\mathrm{TM}}$ Red was oxidized was used. $\mathrm{UV} /$ visible spectra were measured with a JASCO V-630 UV-VIS spectrophotometer (JASCO Co., Tokyo, Japan).

\subsection{Oxidation of EQ 1 by Tyrosinase in the Absence or Presence of L-Ascorbic Acid or a Thiol}

According to the method described by Ito et al. [22], a solution $(2 \mathrm{~mL})$ of $100 \mu \mathrm{M}$ EQ 1 was oxidized by $50 \mathrm{U} / \mathrm{mL}$ tyrosinase at $37^{\circ} \mathrm{C}$ in $50 \mathrm{mM}$ sodium phosphate buffer $(\mathrm{pH} 6.8$ or 5.3). Changes in absorption spectra were periodically followed for $60 \mathrm{~min}$. The oxidation was also carried out in the presence of $1 \mathrm{mM}$ AA or $0.3 \mathrm{mM} \mathrm{NAC}, \mathrm{CySH}$, or GSH. For spectrophotometric analysis, the reference cell contained the same concentrations of buffer, tyrosinase, and AA or a thiol. For HPLC analysis, the reaction was stopped by adding a $200 \mu \mathrm{L}$ aliquot to $200 \mu \mathrm{L} 0.8 \mathrm{M} \mathrm{HClO}_{4}$ or to $20 \mu \mathrm{L} 10 \% \mathrm{NaBH}_{4}(20 \mu \mathrm{L})$ followed by $180 \mu \mathrm{L}$ $0.8 \mathrm{M} \mathrm{HClO}_{4}$.

\subsection{Isolation of EQ-Catechols}

According to the method described by Ito et al. [22], a solution of EQ 1 (24.23 mg, $0.1 \mathrm{mmol})$ and AA $(176.2 \mathrm{mg}, 1.0 \mathrm{mmol})$ in ethanol $(2 \mathrm{~mL})$ was mixed with $98 \mathrm{~mL} 50 \mathrm{mM}$ sodium phosphate buffer ( $\mathrm{pH}$ 6.8). The mixture was vigorously shaken at $37^{\circ} \mathrm{C}$ to which tyrosinase $(20,000 \mathrm{U})$ in $1 \mathrm{~mL}$ buffer was added. After $20 \mathrm{~min}$ of oxidation, $2 \mathrm{~mL} 6 \mathrm{M}$ $\mathrm{HCl}$ was added to stop the oxidation, and the mixture was extracted twice with $100 \mathrm{~mL}$ ethyl acetate. After evaporation of ethyl acetate under reduced pressure, the residue was dissolved in HPLC elution buffer and was subjected to preparative HPLC. After drying each eluate, $6.85 \mathrm{mg}$ (25\% yield) of 6,3'-dihydroxy-EQ 4 (HPLC purity 91\%), $3.00 \mathrm{mg}(12 \%)$ 
of 6-hydroxy-EQ 3 (HPLC purity 91\%), and $6.34 \mathrm{mg}$ (25\%) of 3'-hydroxy-EQ 2 (HPLC purity $100 \%$ ) were obtained.

Hydroxy-EQ (EQ-catechol-A, 2), 6-hydroxy-EQ (EQ-catechol-B, 3), and 6,3'-dihydroxy-EQ (EQ-catechol-C, 4)

The ${ }^{1} \mathrm{H}$ NMR spectra of 3'-hydroxy-EQ 2, 6-hydroxy-EQ 3, and 6,3'-dihydroxy-EQ 4 are shown in Figure S1b-d, respectively. High-resolution ESI-TOF MS analysis of 3'hydroxy-EQ 2, 6-hydroxy-EQ 3, and 6,3'-dihydroxy-EQ 4 gave pseudo-molecular ion peaks at $m / z 257\left([\mathrm{M}-\mathrm{H}]^{-}\right), m / z 257\left([\mathrm{M}-\mathrm{H}]^{-}\right)$, and $m / z 273\left([\mathrm{M}-\mathrm{H}]^{-}\right)$, respectively (Figure S2a-c). 3'-hydroxy-EQ 2 and 6-hydroxy-EQ 3: high-resolution MS 257.0829 and 257.0814, calculated for $\mathrm{C}_{15} \mathrm{H}_{13} \mathrm{O}_{4}, 257.0819$, respectively. 6,3'-dihydroxy-EQ 4: high-resolution MS 273.0765, calculated for $\mathrm{C}_{15} \mathrm{H}_{13} \mathrm{O}_{5}, 273.0768$ (Figure S2a-c, respectively).

\subsection{Isolation of MonoNAC-EQ-Catechol 5 and DiNAC-EQ-Catechol 6}

According to the method described by Ito et al. [22], a solution of EQ 1 (21.8 mg, $0.09 \mathrm{mmol}), 3^{\prime}$-hydroxy-EQ $2(2.58 \mathrm{mg}, 0.01 \mathrm{mmol})$, and NAC $(65.2 \mathrm{mg}, 4.0 \mathrm{mmol})$ in ethanol ( $2 \mathrm{~mL}$ ) was mixed with $98 \mathrm{~mL} 50 \mathrm{mM}$ sodium phosphate buffer ( $\mathrm{pH}$ 6.8). The mixture was vigorously shaken at $37^{\circ} \mathrm{C}$ to which tyrosinase $(20,000 \mathrm{U})$ in $1 \mathrm{~mL}$ buffer was added. After $20 \mathrm{~min}$ of oxidation, $2 \mathrm{~mL} 6 \mathrm{M} \mathrm{HCl}$ was added to stop the oxidation, and the mixture was extracted twice with $100 \mathrm{~mL}$ ethyl acetate. After evaporation of ethyl acetate under reduced pressure, the residue was dissolved in HPLC elution buffer and was subjected to preparative HPLC. After drying each eluate, $2.83 \mathrm{mg}$ ( $5 \%$ yield) DiNAC-EQcatechol 6 (HPLC purity 96\%) and $4.96 \mathrm{mg}$ (12\%) monoNAC-EQ-catechol 5 (HPLC purity $100 \%$ ) were obtained.

\subsubsection{5'-Mono-S-[(N-acetyl)cysteinyl]-3'-hydroxy-EQ (MonoNAC-EQ-catechol, 5)}

The ${ }^{1} \mathrm{H}$ NMR spectrum of monoNAC-EQ-catechol 5 is shown in Figure S3a. ESI(-) MS: $m / z 418\left([\mathrm{M}-\mathrm{H}]^{-}\right)$. High-resolution ESI-TOF MS analysis of the compound gave pseudomolecular ion peaks at $m / z 418\left([\mathrm{M}-\mathrm{H}]^{-}\right)$. High-resolution MS 418.0980, calculated for $\mathrm{C}_{20} \mathrm{H}_{20} \mathrm{NO}_{7} \mathrm{~S}_{1}, 418.0966$ (Figure S4a).

\subsubsection{5,5'-Di-S-[(N-acetyl)cysteinyl]-6,3'-dihydroxy-EQ (DiNAC-EQ-catechol, 6)}

The ${ }^{1} \mathrm{H}$ NMR spectrum of DiNAC-EQ-catechol 6 is shown in Figure S3b. ESI(-) MS: $m / z 595\left([\mathrm{M}-\mathrm{H}]^{-}\right)$. High-resolution MS 595.1069, calculated for $\mathrm{C}_{25} \mathrm{H}_{27} \mathrm{~N}_{2} \mathrm{O}_{11}, 595.1062$ (Figure S4b).

\subsection{Adduct Formation of EQ-Quinones with CySH and GSH and Isolation of GSH Adducts}

According to the method described by Ito et al. [22], a solution of $3^{\prime}$-hydroxy-EQ $2(2.5 \mathrm{mg}, 0.01 \mathrm{mmol})$ and CySH $(4.9 \mathrm{mg}, 0.04 \mathrm{mmol})$ or GSH $(12.4 \mathrm{mg}, 0.04 \mathrm{mmol})$ in $10 \mathrm{~mL}$ of $50 \mathrm{mM}$ sodium phosphate buffer ( $\mathrm{pH} 6.8$ ) was vigorously shaken at $37^{\circ} \mathrm{C}$, to which tyrosinase (2000 U) in $1 \mathrm{~mL}$ of buffer was added. After $10 \mathrm{~min}$ of oxidation, $0.2 \mathrm{~mL}$ of $6 \mathrm{M} \mathrm{HCl}$ was added to stop the oxidation, and the mixture was evaporated to dryness under reduced pressure. The residue was dissolved in HPLC elution buffer and was subjected to preparative HPLC. The CySH adduct was rapidly oxidized and thus could not be isolated. Lyophilization of the faster eluting and slower eluting fractions from GSH gave 5'-monoGS-3'-EQ 7 (3.35 mg, 59\%) and 5,5'-diGS-6,3'-dihydroxy-EQ 8 (0.27 mg, 5\% yield). The ${ }^{1} \mathrm{H}$ NMR and ${ }^{13} \mathrm{C}$ NMR spectra of $5^{\prime}$-monoGS- $3^{\prime}$-EQ 7 and the ${ }^{1} \mathrm{H}$ NMR of 5,5'-diGS-6,3'-dihydroxy-EQ 8 are shown in Figure S5a-f, respectively. The structure of $5^{\prime}$-monoGS-3'-EQ 7 was assigned in detail using shift correlation 2D NMR $\left({ }^{1} \mathrm{H}_{-}{ }^{1} \mathrm{H}\right.$ correlation spectroscopy (COSY)-NMR), ${ }^{1} \mathrm{H}_{-}-{ }^{13} \mathrm{C}$ Heteronuclear single quantum correlation (HSQC)-NMR, and ${ }^{1} \mathrm{H}^{-13} \mathrm{C}$ heteronuclear multiple-bond correlation (HMBC)NMR) (Figure S5d-f). The ${ }^{1} \mathrm{H}$ NMR spectrum of $5^{\prime}$-monoGS-3'-EQ 7 with the 2D double quantum filtered (DQF)-COSY method is shown in Figure S5d. The ${ }^{1} \mathrm{H}$ and ${ }^{13} \mathrm{C}$ NMR spectra of $5^{\prime}$-monoGS-3'-EQ 7 with the 2D HSQC method and the 2D HMBC method are 
shown in Figure S5e,f, respectively. High-resolution ESI-TOF MS analysis of 5'-monoGS-3'EQ 7 gave pseudo-molecular ion peaks at $m / z 586\left([\mathrm{M}+\mathrm{Na}]^{+}\right)$(Figure S6a). The positions of two GSH groups in the benzene ring of 5,5'-diGS-6,3'-dihydroxy-EQ 8 were assigned by the positions of three protons: $6.36 \mathrm{ppm}(1 \mathrm{H}, \mathrm{s}), 6.72 \mathrm{ppm}(1 \mathrm{H}, \mathrm{d}, \mathrm{J}=2.0 \mathrm{~Hz})$, and $6.83 \mathrm{ppm}$ $(1 \mathrm{H}, \mathrm{d}, \mathrm{J}=2.0 \mathrm{~Hz})$ (Figure S5c). This pattern of the positions of three protons in the benzene ring was the same as that in 5,5'-diNAC-6,3'-dihydroxy-EQ 6 (Figure S3b): $6.34 \mathrm{ppm}(1 \mathrm{H}$, s), $6.69 \mathrm{ppm}(1 \mathrm{H}, \mathrm{d}, \mathrm{J}=2 \mathrm{~Hz})$, and $6.85 \mathrm{ppm}(1 \mathrm{H}, \mathrm{d}, \mathrm{J}=2.0 \mathrm{~Hz})$. High-resolution ESI-TOF MS analysis of the di-GSH adducts gave pseudo-molecular ion peaks at $m / z 907\left([\mathrm{M}+\mathrm{Na}]^{+}\right)$ (Figure S6b). The ${ }^{1} \mathrm{H}$ NMR of EQ metabolites (2, 3, 4, 5, and 6) are summarized in Table S1. ${ }^{1} \mathrm{H}$ and ${ }^{13} \mathrm{C}$ NMR spectra of $5^{\prime}$-monoGS-3'-EQ 7 are summarized in Table S2. The number of GSH additions was confirmed by MS analysis. 5'-monoGS-3'-EQ 7; ESI(+) MS: $m / z$ $586\left([\mathrm{M}+\mathrm{Na}]^{+}\right)$, high-resolution ESI-TOF MS 586.1466, calculated for $\mathrm{C}_{25} \mathrm{H}_{29} \mathrm{~N}_{3} \mathrm{NaO}_{10} \mathrm{~S}$, 586.1466 (Figure S6a). 5,5'-diGS-6,3'-dihydroxy-EQ 8; ESI(+) MS: $m / z 907\left([\mathrm{M}+\mathrm{Na}]^{+}\right)$, high-resolution MS 907.2099, calculated for $\mathrm{C}_{35} \mathrm{H}_{44} \mathrm{~N}_{6} \mathrm{NaO}_{17} \mathrm{~S}_{2}, 907.2097$ (Figure S6b).

\subsection{Metabolism of EQ 1 in Tyrosinase-Transfected Cells}

293T cells $\left(0.75 \times 10^{6}\right)$ were transfected with the human tyrosinase gene. The expression plasmid pcDNA3.1 containing the coding sequence of human TYR gene was transiently transfected using Lipofectamine 2000 Reagent (Invitrogen, Carlsbad, CA, USA) according to the manufacturer's protocol. The cells were then incubated in DMEM, and, $24 \mathrm{~h}$ later, the medium $(0.75 \mathrm{~mL})$ was replaced with medium containing $0.0,0.05,0.1$, and $0.2 \mathrm{mM}$ EQ 1. The incubation was then continued for $2 \mathrm{~h}$. Medium samples $(0.18 \mathrm{~mL})$ were deprotonated with $4 \mathrm{M} \mathrm{HClO}_{4}$ at $4{ }^{\circ} \mathrm{C}$ for $60 \mathrm{~min}$. Cell samples $\left(0.75 \times 10^{6}\right)$ were extracted with $0.4 \mathrm{M} \mathrm{HClO}_{4}$ by shaking vigorously for $60 \mathrm{~min}$. After centrifugation at $10,000 \times g$ for $3 \mathrm{~min}$, the supernatants were analyzed by HPLC as described below.

Concentrations of EQ 1 remaining in the medium or taken up in cells were analyzed using a mobile phase of $0.4 \mathrm{M} \mathrm{HCOOH}$ : methanol $=50: 50(v / v)$ at $45^{\circ} \mathrm{C}$ with a flow rate of $0.7 \mathrm{~mL} / \mathrm{min}$ and a wavelength of $280 \mathrm{~nm}$. EQ 1 appeared at $10.9 \mathrm{~min}$ under these conditions. Concentrations of EQ-quinone adducts of $\mathrm{CySH}$ and $\mathrm{GSH}$ in the medium or in cells were analyzed using a mobile phase of $0.4 \mathrm{M} \mathrm{HCOOH}$ : methanol $=70: 30(v / v)$ at $45^{\circ} \mathrm{C}$ with a flow rate of $0.7 \mathrm{~mL} / \mathrm{min}$. To detect low levels of those adducts, an electrochemical detector with an applied voltage of $600 \mathrm{mV}$ was used.

\subsection{Pro-Oxidant Activity of the EQ 1 Oxidation Product, EQ-Oligomer}

According to the method described by Ito et al. [22], the EQ-oligomer was prepared in $50 \mathrm{mM}$ sodium phosphate buffer (pH 7.4) from EQ 1 (1 mM). Tyrosinase (200 U) was added to the $2 \mathrm{~mL}$ precursor solution, and the mixture was incubated at $37^{\circ} \mathrm{C}$ for $120 \mathrm{~min}$. Tyrosinase alone $(100 \mathrm{U} / \mathrm{mL})$ was used as a control. The melanin solutions $(2 \mathrm{~mL})$ were mixed with $10 \mathrm{mM} \mathrm{GSH}\left(200 \mu \mathrm{L}, 1 \mathrm{~mol}\right.$ eq.) and were incubated at $37^{\circ} \mathrm{C}$. At 0,30 , and $60 \mathrm{~min}$ reaction times, $100 \mu \mathrm{L}$ aliquots were withdrawn and mixed with $0.4 \mathrm{M} \mathrm{HClO}_{4}$ $(800 \mu \mathrm{L})$ to terminate the oxidation. GSH and GSSG in the oxidation mixtures were analyzed using the HPLC method described by Imai et al. [37]. The HPLC system was modified from the original conditions as follows: a mobile phase of 0.4 M HCOOH: methanol, 30:70 $(v / v)$ was used with a UV detector at $294 \mathrm{~nm}$ and a column temperature of $45^{\circ} \mathrm{C}$.

According to the method described by Ito et al. [22], $\mathrm{H}_{2} \mathrm{O}_{2}$ was analyzed spectrophotometrically after dilution with the $\mathrm{pH} 7.4$ buffer. Briefly, the oxidation mixture $(20 \mu \mathrm{L})$ was diluted with pH 7.4 buffer $(180 \mu \mathrm{L})$, and the diluted mixture $(200 \mu \mathrm{L})$ was reacted with the chromogen Ampliflu ${ }^{\mathrm{TM}}$ Red reagent $(200 \mu \mathrm{L})$ to form a red pigment with an absorption maximum at $568 \mathrm{~nm}$ [41], closely following the manufacturer's instructions (Invitrogen, Tokyo, Japan). The mixture was left at room temperature for $10 \mathrm{~min}$. Absorption spectra were measured between 450 and $650 \mathrm{~nm}$. 


\subsection{Statistical Analyses}

Student's $t$-tests (two-tailed) were performed using Microsoft Excel for Mac (Japan Microsoft Co., Tokyo, Japan). A $p$-value of $<0.05$ was considered statistically significant.

\section{Conclusions}

EQ-quinones generated by the oxidation of EQ 1 in the presence of tyrosinase reacted with NAC, $\mathrm{CySH}, \mathrm{GSH}$, and BSA through the CySH residue. EQ 1 was also oxidized to EQ-quinones in cells expressing human tyrosinase. The EQ-oligomer can oxidize GSH to GSSG, indicating its pro-oxidant activity. These results suggest that EQ-quinones could be cytotoxic to melanocytes due to the binding of EQ-quinones to their proteins. Although EQ 1 has various beneficial effects on human health, it is considered necessary to use EQ 1 with the utmost care when applying it for cosmetic purposes.

Supplementary Materials: Supplementary Materials can be found at https://www.mdpi.com/ article/10.3390/ijms22179145/s1.

Author Contributions: Conception and design: H.T., S.I., T.N.-M., K.K. and K.W.; experiment and data collection: H.T., S.I., T.N.-M. and M.O.; data analysis: H.T., T.N.-M., S.I., M.O. and K.W.; drafting of manuscript: H.T., T.N.-M., S.I. and K.W. All authors have read and agreed to the published version of the manuscript.

Funding: This research was supported in part by a Japan Health, Labour and Welfare Policy Research Grant (19KC2005) given to S.I. and T.N.-M. We also acknowledge support of The Cosmetology Research Foundation to K.W.

Institutional Review Board Statement: Not applicable.

Informed Consent Statement: Not applicable.

Conflicts of Interest: The authors declare no conflict of interest.

$\begin{array}{ll}\text { Abbreviations } & \\ \text { AA } & \text { L-Ascorbic acid } \\ \text { Ampliflu' }{ }^{\mathrm{TM}} \text { Red reagent } & \text { 10-Acetyl-3,7-dihydroxyphenoxazine } \\ \text { BSA } & \text { Bovine serum albumin } \\ \text { COSY } & \text { Correlation spectroscopy } \\ \text { CySH } & \text { Cysteine } \\ \text { DBBQ } & \text { 3,5-di-tert.-butyl-1,2-benzoquinone } \\ \text { DMEM } & \text { Dulbecco's modified eagle's medium } \\ \text { DQF } & \text { Double quantum filtered } \\ \text { DTNB } & \text { 5.5'-Dithiobis (2-nitrobenzoic acid) } \\ \text { ER } & \text { Endoplasmic reticulum } \\ \text { EQ } & \text { Equol (7-hydroxy-3-(4'-hydroxyphenyl)-chroman) } \\ \text { ESI } & \text { Electrospray ionization } \\ \text { GSH } & \text { Glutathione } \\ \text { GSSG } & \text { Oxidized glutathione } \\ \text { HMBC } & \text { Heteronuclear multiple-bond correlation } \\ \text { HPLC } & \text { High-performance liquid chromatography } \\ \text { HSQC } & \text { Heteronuclear single quantum correlation } \\ \text { NAC } & N \text {-Acetyl-L-cysteine } \\ \text { NEM } & N \text {-Ethylmaleimide } \\ \text { NMR } & \text { Nuclear magnetic resonance } \\ \text { SOD } & \text { Superoxide dismutase } \\ \text { TOF MS } & \text { Time of flight mass spectrometry } \\ \text { TRP-1 } & \text { Tyrosinase-related protein-1 } \\ \text { TRP-2 } & \text { Tyrosinase-related protein-2 } \\ \text { UV } & \text { Ultraviolet } \\ & \end{array}$




\section{References}

1. Setchell, K.D.R.; Clerici, C. Equol: Pharmacokinetics and biological actions. J. Nutr. 2010, 140, 1363S-1368S. [CrossRef]

2. Mayo, B.; Vázquez, L.; Flórez, A.B. Equol: A bacterial metabolite from the daidzein isoflavone and its presumed beneficial health effects. Nutrients 2019, 11, 2231. [CrossRef]

3. Marrian, G.F.; Haslewood, G.A. Equol, a new inactive phenol isolated from the ketohydroxyoestrin fraction of mares' urine. Biochem. J. 1932, 26, 1227-1232. [CrossRef]

4. Setchell, K.D.; Clerici, C. Equol: History, chemistry, and formation. J. Nutr. 2010, 140, 1355S-1362S. [CrossRef]

5. Bennetau-Pelissero, C.; Arnal-Schnebelen, B.; Lamothe, V.; Sauvant, P.; Sagne, J.L.; Verbruggen, M.A.; Mathey, J.; Lavialle, O. ELISA as a new method to measure genistein and daidzein in food and human fluids. Food Chem. 2003, 82, 645-658. [CrossRef]

6. Schwen, R.J.; Nguyen, L.; Charles, R.L. Elucidation of the metabolic pathway of S-equol in rat, monkey and man. Food Chem. Toxicol. 2012, 50, 2074-2083. [CrossRef]

7. Kim, M.; Kim, S.I.; Han, J.; Wang, X.L.; Song, D.G.; Kim, S.U. Stereospecific biotransformation of dihydrodaidzein into (3S)-equol by the human intestinal bacterium Eggerthella strain Julong 732. Appl. Environ. Microbiol. 2009, 75, 3062-3068. [CrossRef]

8. Setchell, K.D.; Clerici, C.; Lephart, E.D.; Cole, S.J.; Heenan, C.; Castellani, D.; Wolfe, B.E.; Nechemias-Zimmer, L.; Brown, N.M.; Lund, T.D.; et al. S-equol, a potent ligand for estrogen receptor beta, is the exclusive enantiomeric form of the soy isoflavone metabolite produced by human intestinal bacterial flora. Am. J. Clin. Nutr. 2005, 81, 1072-1079. [CrossRef]

9. Lund, T.D.; Munson, D.J.; Haldy, M.E.; Setchell, K.D.; Lephart, E.D.; Handa, R.J. Equol is a novel anti-androgen that inhibits prostate growth and hormone feedback. Biol. Reprod. 2004, 70, 1188-1195. [CrossRef]

10. Choi, E.J.; Kim, G.H. The antioxidant activity of daidzein metabolites, O-desmethylangolensin and equol, in HepG2 cells. Mol. Med. Rep. 2014, 9, 328-332. [CrossRef]

11. Wei, X.J.; Wu, J.; Ni, Y.D.; Lu, L.Z.; Zhao, R.Q. Antioxidant effect of a phytoestrogen equol on cultured muscle cells of embryonic broilers. In Vitro Cell. Dev. Biol. Anim. 2011, 47, 735-741. [CrossRef]

12. Jackson, R.L.; Greiwe, J.S.; Schwen, R.J. Emerging evidence of the health benefits of S-equol, an estrogen receptor $\beta$ agonist. Nutr. Rev. 2011, 69, 432-448. [CrossRef]

13. Nishigori, C.; Aoyama, Y.; Ito, A.; Suzuki, K.; Suzuki, T.; Tanemura, A.; Ito, M.; Katayama, I.; Oiso, N.; Kagohashi, Y.; et al. Guide for medical professionals (i.e. dermatologists) for the management of Rhododenol-induced leukoderma. J. Dermatol. 2015, 42, 113-128. [CrossRef]

14. Sasaki, M.; Kondo, M.; Sato, K.; Umeda, M.; Kawabata, K.; Takahashi, Y.; Suzuki, T.; Matsunaga, K.; Inoue, S. Rhododendrol, a depigmentation-inducing phenolic compound, exerts melanocyte cytotoxicity via a tyrosinase-dependent mechanism. Pigment. Cell Melanoma Res. 2014, 27, 754-763. [CrossRef]

15. Ito, S.; Okura, M.; Nakanishi, Y.; Ojika, M.; Wakamatsu, K.; Yamashita, T. Tyrosinase-catalyzed metabolism of rhododendrol (RD) in B16 melanoma cells: Production of RD-pheomelanin and covalent binding with thiol proteins. Pigment. Cell Melanoma Res. 2015, 28, 295-306. [CrossRef]

16. Ito, S.; Wakamatsu, K. Biochemical mechanism of rhododendrol-induced leukoderma. Int. J. Mol. Sci. 2018, 19, e552. [CrossRef]

17. Ito, S.; Okura, M.; Wakamatsu, K.; Yamashita, T. The potent pro-oxidant activity of rhododendrol-eumelanin induces cysteine depletion in B16 melanoma cells. Pigment. Cell Melanoma Res. 2017, 30, 63-67. [CrossRef]

18. Colica, C.; Milanovi 'c, M.; Mili 'c, N.; Aiello, V.; De Lorenzo, A.; Abenavoli, L. A Systematic Review on Natural Antioxidant Properties of Resveratrol. Nat. Prod. Commun. 2018, 13. [CrossRef]

19. Xiao, Q.; Zhu, W.; Feng, W.; Lee, S.S.; Leung, A.W.; Shen, J.; Gao, L.; Xu, C. A Review of Resveratrol as a Potent Chemoprotective and Synergistic Agent in Cancer Chemotherapy. Front. Pharmacol. 2019, 9, 1534. [CrossRef]

20. Na, J.I.; Shin, J.W.; Choi, H.R.; Kwon, S.H.; Park, K.C. Resveratrol as a multifunctional topical hypopigmenting agent. Int. J. Mol. Sci. 2019, 20, E956. [CrossRef]

21. Park, J.; Park, J.H.; Suh, H.-J.; Lee, I.C.; Koh, J.; Boo, Y.C. Effects of resveratrol, oxyresveratrol, and their acetylated derivatives on cellular melanogenesis. Arch. Dermatol. Res. 2014, 306, 475-487. [CrossRef]

22. Ito, S.; Fujiki, Y.; Matsui, N.; Ojika, M.; Wakamatsu, K. Tyrosinase-catalyzed oxidation of resveratrol produces a highly reactive ortho-quinone: Implications for melanocyte toxicity. Pigment. Cell Melanoma Res. 2019, 32, 766-776. [CrossRef] [PubMed]

23. Shaito, A.; Posadino, A.M.; Younes, N.; Hasan, H.; Halabi, S.; Alhababi, D.; Al-Mohannadi, A.; Abdel-Rahman, W.M.; Eid, A.H.; Nasrallah, G.K.; et al. Potential adverse effects of resveratrol: A literature review. Int. J. Mol. Sci. 2019, 21, 2084. [CrossRef] [PubMed]

24. Mortensen, A.; Kulling, S.E.; Schwartz, H.; Rowland, I.; Ruefer, C.E.; Rimbach, G.; Cassidy, A.; Magee, P.; Millar, J.; Hall, W.L.; et al. Analytical and compositional aspects of isoflavones in food and their biological effects. Mol. Nutr. Food Res. 2009, 53, S266-S309. [CrossRef] [PubMed]

25. Ishimi, Y. Soybean isoflavones in bone health. Forum Nutr. 2009, 61, 104-116. [CrossRef] [PubMed]

26. Steiner, C.; Arnould, S.; Scalbert, A.; Manach, C. Isoflavones and the prevention of breast and prostate cancer: New perspectives opened by nutrigenomics. Br. J. Nutr. 2008, 99, ES78-ES108. [CrossRef] [PubMed]

27. Ito, S.; Ojika, M.; Yamashita, T.; Wakamatsu, K. Tyrosinase-catalyzed oxidation of rhododendrol produces 2-methylchromane-6,7dione, the putative ultimate toxic metabolite: Implications for melanocyte toxicity. Pigment. Cell Melanoma Res. 2014, $27,744-753$. [CrossRef] 
28. Lee, P.-G.; Lee, U.-J.; Song, H.; Choi, K.-Y.; Kim, B.-G. Recent advances in the microbioal hydroxylation and reduction of soy isoflavones. FEMS Micro. Lett. 2018, 365, fny195. [CrossRef]

29. Ito, S.; Hinoshita, M.; Suzuki, E.; Ojika, M.; Wakamatsu, K. Tyrosinase-catalyzed oxidation of the leukoderma-inducing agent Raspberry ketone produces (E)-4-(3-oxo-1-butenyl)-1,2-benzoquinone: Implications for melanocyte toxicity. Chem. Res. Toxicol. 2017, 30, 859-868. [CrossRef]

30. Niwa, T.; Akiyama, H.; Echikawa, M.; Yokoyama, S.-I.; Mochizuki, M.; Osawa, T. Equol inhibits mushroom tyrosinase in vitro through tight binding. Biol. Pharm. Bull. 2020, 43, 550-553. [CrossRef]

31. Shinkaruk, S.; Carreau, C.; Flouriot, G.; Bennetau-Pelissero, B.; Potier, M. Comparative effects of R-and S-equol and implication of transactivation functions (AF-1 and AF-2) in estrogen receptor-induced transcriptional activity. Nutrients 2010, 2, 340-354 [CrossRef]

32. Wang, X.-L.; Hur, H.-G.; Lee, J.H.; Kim, K.T.; Kim, S.-I. Enantioselective synthesis of S-Equol from dihydrodaidzein by a newly isolated anaerobic human intestinal bacterium. All. Environ. Microbiol. 2005, 71, 214-219. [CrossRef] [PubMed]

33. Rüfer, E.; Glatt, H.; Kulling, S.E. Structural elucidation of hydroxylated metabolites of the isoflavan equol by gas chromatographymass spectrometry and high-performance liquid chromatography-mass spectrometry. Amer. Soc. Pharmacol. Therap. 2006, 34, 51-60. [CrossRef] [PubMed]

34. Manini, P.; Napolitano, A.; Westerhof, W.; Riley, P.A.; d'Ischia, M. A reactive ortho-quinone generated by tyrosinase-catalyzed oxidation of the skin depigmenting agent monobenzone: Self-coupling and thiol-conjugation reactions and possible implications for melanocyte toxicity. Chem. Res. Toxicol. 2009, 22, 1398-1405. [CrossRef] [PubMed]

35. Simonova, M.; Wall, A.; Weissleder, R.; Bogdanov, A., Jr. Tyrosinase mutants are capable of prodrug activation in transfected nonmelanotic cells. Cancer Res. 2000, 60, 6656-6662.

36. Cordes, P.; Sun, W.; Wolber, R.; Kolbe, L.; Klebe, G.; Rohm, K.H. Expression in non-melanogenic systems and purification of soluble variants of human tyrosinase. Biol. Chem. 2013, 394, 685-693. [CrossRef] [PubMed]

37. Imai, Y.; Ito, S.; Fujita, K. Determination of natural thiols by liquid chromatography after derivatization with 3,5-di-tert.-butyl-1,2benzoquinone. J. Chromatogr. 1987, 420, 404-410. [CrossRef]

38. Chang, C.J.; Tsai, T.Y. Antimelanogenic effects of the novel melanogenic inhibitors daidzein and equol, derived from soymilk fermented with Lactobacillus plantarum strain TWK10, in B16F0 mouse melanoma cells. J. Funct. Foods 2016, 22, 211-223. [CrossRef]

39. Ito, S.; Gerwat, W.; Kolbe, L.; Yamashita, T.; Ojika, M.; Wakamatsu, K. Human tyrosinase is able to oxidize both enantiomers of rhododendrol. Pigment. Cell Melanoma Res. 2014, 27, 1149-1153. [CrossRef]

40. Yang, L.; Yang, F.; Wataya-Kaneda, M.; Tanemura, A.; Tsuruta, D.; Katayama, I. 4-(4-hydroroxyphenyl)-2-butanol (rhododendrol) activates the autophagy-lysosome pathway in melanocytes: Insights into the mechanisms of rhododendrol-induced leukoderma. J. Dermatol. Sci. 2015, 77, 182-185. [CrossRef]

41. Zhou, M.; Panchuk-Voloshina, N. A one-step fluorometric method for the continuous measurement of monoamine oxidase activity. Anal. Biochem. 1997, 253, 169-174. [CrossRef] [PubMed] 